\title{
Diabetes-associated infections: development of antimicrobial resistance and possible treatment strategies
}

\author{
Muhammad Sajid Hamid Akash $^{1}$ (1) $\cdot$ Kanwal Rehman $^{2} \cdot$ Fareeha Fiayyaz $^{1,3} \cdot$ Shakila Sabir $^{1,4} \cdot$ Mohsin Khurshid $^{3}$
}

Received: 15 September 2019 / Revised: 19 January 2020 / Accepted: 22 January 2020 / Published online: 3 February 2020

๑) Springer-Verlag GmbH Germany, part of Springer Nature 2020

\begin{abstract}
Diabetes mellitus is associated with various types of infections notably skin, mucous membrane, soft tissue, urinary tract, respiratory tract and surgical and/or hospital-associated infections. The reason behind this frequent association with infections is an immunocompromised state of diabetic patient because uncontrolled hyperglycemia impairs overall immunity of diabetic patient via involvement of various mechanistic pathways that lead to the diabetic patient as immunocompromised. There are specific microbes that are associated with each type of infection and their presence indicates specific type of infections. For instance, E. coli and Klebsiella are the most common causative pathogens responsible for the development of urinary tract infections. Diabetic-foot infections commonly occur in diabetic patients. In this article, we have mainly focused on the association of diabetes mellitus with various types of bacterial infections and the pattern of resistance against antimicrobial agents that are frequently used for the treatment of diabetes-associated infections. Moreover, we have also summarized the possible treatment strategies against diabetes-associated infections.
\end{abstract}

Keywords Diabetic-foot infections $\cdot$ Diabetes-associated surgical site infections $\cdot$ Antimicrobial resistance

\section{Introduction}

Diabetes mellitus (DM) is a chronic metabolic disorder and one of the major causes of morbidity globally (Matusda and De Fronzo 1999). It is estimated that risk of DM will be greatly increased in the future. Between 1990 and 2010, the incidence of DM nearly tripled with 1.9 million new cases diagnosed in 2010 in USA (Yu et al. 2014). According to the World Health Organization, America, Bangladesh, India,

Communicated by Erko Stackebrandt.

Muhammad Sajid Hamid Akash

sajidakash@gmail.com

$\triangle$ Kanwal Rehman

kanwalakash@gmail.com

1 Department of Pharmaceutical Chemistry, Government College University, Faisalabad, Pakistan

2 Department of Pharmacy, University of Agriculture, Faisalabad, Pakistan

3 Department of Microbiology, Government College University, Faisalabad, Pakistan

4 Department of Pharmacology, Government College University, Faisalabad, Pakistan
Italy, Brazil, Russia, Pakistan, China, Japan and Indonesia, are the top ten countries with highest number of diabetic patients (Noor et al. 2015). T2DM is a heterogeneous group of disorders characterized by impaired insulin secretion, variable degrees of insulin resistance, and increased glucose production which is more common and mainly known disease of the elderly age. In adults, there is increased chance of early-onset of DM especially in industrialized countries. In 2011, the incidence of DM in people older than 65 years was $26.9 \%$ in USA and $11.3 \%$ in people older than 20 years (Apelqvist et al. 2000).

DM is a known risk factor for certain infectious diseases because diabetic individuals are in an immunocompromised due to their uncontrolled diabetes mellitus notably hyperglycemia (Shah and Hux 2003; Muller et al. 2005). Due to which there is a higher risk of number of other medical complications including eye problems and blindness, cardiovascular disease, lower extremity amputations and renal disease in diabetic individuals as compared to that in nondiabetic individuals. Among the various causative factors, hyperglycemia is one of the main culprits to impair the overall immunity of diabetic patient via involvement of various mechanistic pathways. Immunocompromised state is invariable in all diabetic patients. Not all diabetic patients are 
immune-compromised except those patients having uncontrolled diabetes are considered immunocompromised due to negative effects of hyperglycemic environment that favors immune dysfunction such as damage to neutrophil function, impairment of antioxidant system and humoral immunity as shown in Fig. 1 (Casqueiro et al. 2012a; Calliari et al. 2019). High blood glucose impairs both innate and adaptive immunity through various mechanisms. Chronic hyperglycemia in diabetic patients can result in acidosis, which reduces the activity of immune system. Upon treatment of acidosis and hyperglycemia, the effects can be reversible (Casqueiro et al. 2012b). Immune-compression is a heterogeneous group of diseases affecting various components of the immune system. The immune-compromised states can lead to different disorders that results in impairment of human immune system including human immunodeficiency virus infection, primary immune deficiency, and immunosuppression-related medical treatment, such as high-dose corticosteroid uses or transplantation therapy. Among these, human immunodeficiency virus infections are the most notorious. Clinical complications in immune-compromised patients vary from severe infections to unusual malignancies affecting major organs (Zheng and Zhang 2014).

In this article, we have summarized the findings of studies related to the association of DM with infectious diseases and risk of infection that is more common in diabetic patients. We have also focused that how antimicrobial resistance is developed during infection against antibiotics given to the diabetic patient. Furthermore, we have also provided the possible treatment strategies against DM-associated infections.

\section{Urinary tract infections in diabetic conditions}

Diabetic patients are at increased risk of infectious diseases and most important and frequent site of infection is urinary tract (Patterson and Andriole 1997; Joshi et al. 1999; Shah and Hux 2003; Boyko et al. 2005). In general population, one of the most common bacterial infection is urinary tract infections with an overall estimated rate of incidence of 17.5/1000 person in a year (Laupland et al. 2007). In American study conducted on a health service data base with more than 70,000 patients with type 2 diabetes, it has been found that $8.2 \%$ were diagnosed with urinary tract infection during 1 year with incidence increasing with age (Yu et al. 2014). In another database study, it was also found that urinary tract infections were more common in diabetic patients as compared to that of non-diabetic patients among 89,790 matched pairs of patients with and without type 2 diabetes mellitus (Fu et al. 2014). Patients with DM are at increased risk of developing acute pyelonephritis, asymptomatic bacteriuria and other complications of urinary tract infections. For the development of symptomatic urinary tract infections and asymptomatic bacteriuria, the most common causative agents are K. pneumoniae and E. coli (Ribera et al. 2006). It has been warned that urinary tract infections would be positioned among the top ten concurrent or complicating illnesses during the lifetime course for the management of DM (Wheat 1980). It has been reported that up to $50 \%$ of women had at least one urinary tract infection during

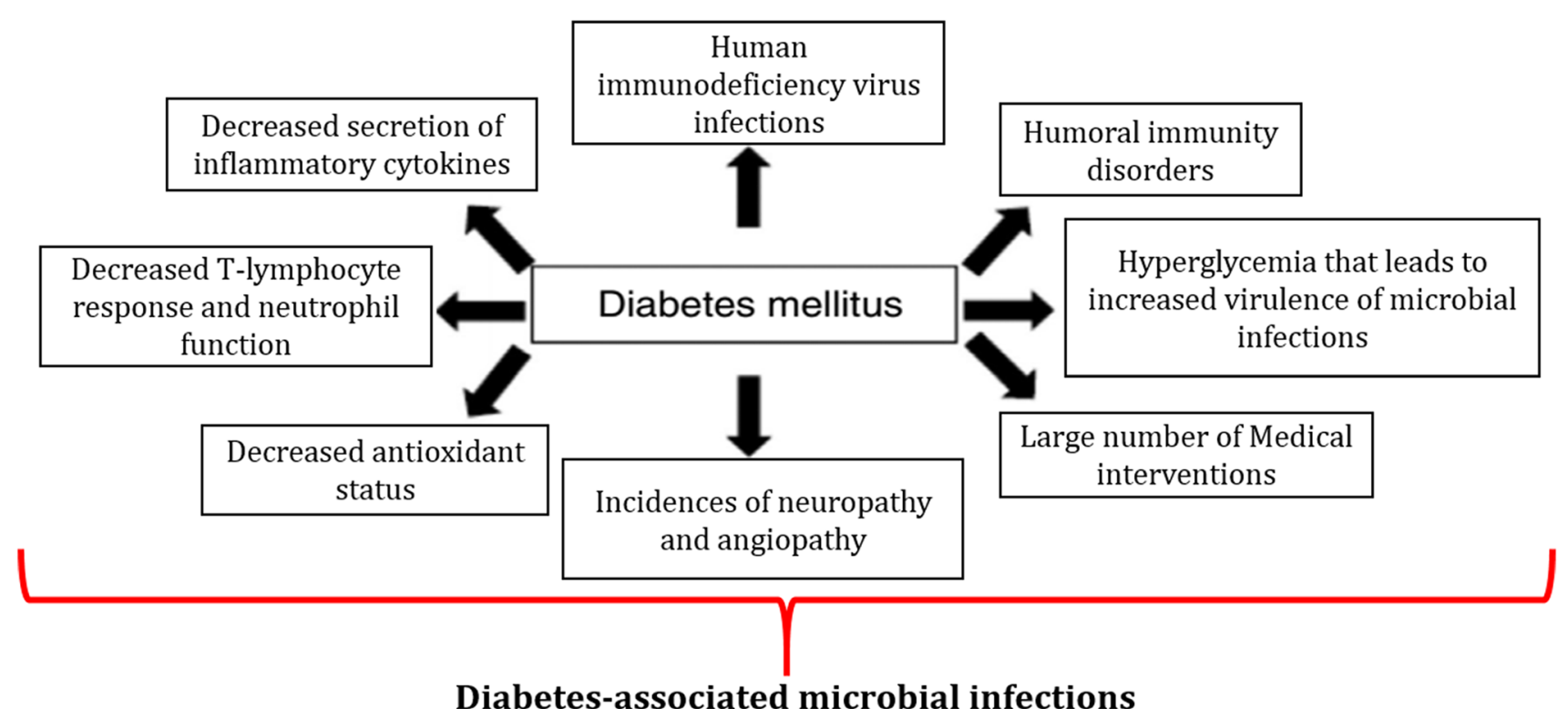

Fig. 1 Schematic representation of pathogenesis of diabetes-associated infections. Adapted from (Casqueiro et al. 2012a; Calliari et al. 2019) 
their period of life (Barnett and Stephens 1997). More severe manifestations of urinary tract infections seemed to be associated with T2DM. A 12-month prospective cohort study proved that like T2DM, patients with T1DM are also at higher risk of urinary tract infections, lower respiratory tract infection as well as skin and soft tissues infections, indicating increased risks of common infections in both type 1 and type 2 diabetes (Muller et al. 2005). Similar to T2DM, T1DM is also mainly engaged with impairment in innate and adaptive immune system, ultimately leading towards increased risk of infections. Several evidences have suggested that hyperglycemia is the promoting factor for bacterial infections, also leading towards increased consumption of antibiotics. Additionally, these infections may lead to kidney injury either by direct invasion of pathogen or endotoxin, causing further complications (Simonsen et al. 2015). Asymptomatic bacteriuria to lower urinary tract infections, pyelonephritis, and severe urosepsis are the spectrum of urinary tract infections in patients suffering from DM. Emphysematous cystitis and pyelonephritis, renal abscesses and renal papillary necrosis are serious complications occurring in urinary tract infections. All these complications are frequently found in T2DM as compared to general population (Kofteridis et al. 2009; Mnif et al. 2013). In one study, the probability of hospital-acquired acute pyelonephritis was estimated to increase in case of DM by 20 to 30-fold in patients with less than 44 years of age, while, in patients over the age of 44 years, probability was 3-5-fold (Nicolle et al. 1996). Incidence of bilateral kidney infection also found to be increased in patients with DM (Hakeem et al. 2009). Additionally, there are more chances of bacteremia in diabetic patients owing urinary tract infections in comparison to non-diabetic individuals (Carton et al. 1992).

Several factors are associated with increased risk of urinary tract infections in diabetic patients includes, long term complications, metabolic control, age, primarily diabetic cystopathy and nephropathy (Brown et al. 2005). 22 observational studies (5 follow-up and 16 cross-sectional studies) published between 1966 and 2007 have reported that there is risk of asymptomatic bacteriuria in diabetic patients. Metaanalysis revealed that the chances of asymptomatic bacteriuria was found in $12.2 \%$ diabetic patients which was less likely to occur in $4.5 \%$ of patients that were taken from the healthy control group. In both women and men, prevalence of asymptomatic bacteriuria was higher either with DM or compared with healthy controls (Raz 2003). Recently, a study conducted on health service database with more than 70,000 patients with T2DM, has found that $8.2 \%$ were diagnosed with urinary tract infections during 1 year (Yu et al. 2014). In this study, it was also found that urinary tract infections were more common in men and women with DM than in those individuals without DM.

\section{Bacteriology of urinary tract infections in diabetic conditions}

Bacteria that are more likely to involve in urinary tract infections are found to be similar in both the individuals with and without DM but also elicits complicated urinary tract infections (Nicolle 2001). In diabetic patients, identified bacteria, i.e., Enterococcus spp. (4\%), Staphylococcus spp. (5\%), Klebsiella spp. (6\%), and E. coli (71\%). Enterococcus spp. were more commonly found than Klebsiella spp. and Staphylococcus spp. in patients without DM. Rates of other species such as Proteus spp., Pseudomonas spp. and other bacteria such as Streptococcus $B$ were found close in both groups of individuals (Table 1) (Malmartel and Ghasarossian 2016). As E. coli causes majority of infections in uncomplicated urinary tract infections. However, in these patients, other strains are also cultured frequently. For example, one study reported that $47 \%$ of urinary tract infections in diabetic patients and $68 \%$ chance of urinary tract infections in non-diabetic patients was due to more common uropathogen named as E. coli (Lye et al. 1992). Uropathogen other than $E$. coli also found in diabetic individuals, include Enterococcus faecalis, Proteus spp., Klebsiella spp., Enterobacter spp., and Group B Streptococci (Cook et al.
Table 1 Bacteria responsible for urinary tract infection in patients with and without diabetes mellitus after matching. Adopted from (Malmartel and Ghasarossian 2016)

\begin{tabular}{lllllll}
\hline Bacteria & $\begin{array}{l}\text { Patients } \\
\text { with dia- } \\
\text { betes } \\
N=124 \\
(\%)\end{array}$ & $\begin{array}{l}\text { Patients } \\
\text { without } \\
\text { diabetes } \\
N=246(\%)\end{array}$ & $P$ value & $\begin{array}{l}\text { Patients with } \\
\text { uncontrolled } \\
\text { diabetes } \\
N=100(\%)\end{array}$ & $\begin{array}{l}\text { Patients with } \\
\text { controlled } \\
\text { diabetes } \\
N=24(\%)\end{array}$ & $P$ value \\
\hline Escherichia coli & $88(71)$ & $169(69)$ & 0.74 & $72(72)$ & $16(67)$ & 0.79 \\
Enterococcus spp. & $5(4)$ & $25(10)$ & 0.07 & $5(5)$ & 0 & - \\
Klebsiella spp. & $8(6)$ & $11(4)$ & 0.57 & $5(5)$ & $3(13)$ & 0.17 \\
Proteus spp. & $3(2)$ & $10(4)$ & 0.56 & $3(3)$ & 0 & - \\
Staphylococcus spp. & $6(5)$ & $6(2)$ & 0.23 & $4(4)$ & $2(8)$ & 0.3 \\
Pseudomonas spp. & $1(1)$ & $11(4)$ & 0.07 & $1(1)$ & 0 & - \\
Other bacteria & $13(10)$ & $14(6)$ & 0.14 & $10(10)$ & $3(13)$ & 0.7 \\
\hline
\end{tabular}


1989; Zhanel et al. 1990b, 1995). Some studies have also noted that patients with DM are at greater chance of getting infection from a resistant uropathogen (Johnson and Stamm 1989; Lye et al. 1992).

\section{Antimicrobial resistance in urinary tract infections in diabetic conditions}

It has been observed that isolated strains of $E$. coli show similar rates of resistance against nitrofurantoin, ciprofloxacin, ampicillin and co-trimoxazole in both diabetic and nondiabetic patients. An association has been found between the presence of co-trimoxazole resistance and DM due to recent hospitalization and use of the same drug (Wright et al. 1999) but no correlation has been reported between $E$. coli resistance against co-trimoxazole or quinolones and DM in out-patients (Steinke et al. 1999; Meiland et al. 2004).

\section{Treatment strategies for urinary tract infections in diabetic conditions}

\section{Antimicrobial treatment}

Regarding the outcomes of treatment strategies for asymptomatic bacteriuria in patients with DM, few clinical trials have been conducted (Forland et al. 1977; Forland and Thomas 1985). The results of these clinical trials indicate that (1) 2 weeks and 6 weeks of treatment have same effectiveness; (2) the rate of recurrence of urinary tract infection was high, even after following antibiotic treatment for longer duration; (3) mostly re-infections were recurrent (4/8 weeks post-therapy) and these reversions were not with same microorganism. Among bacteriuric women with DM, physician should have awareness about high prevalence of underlying structural genitourinary abnormalities (Forland and Thomas 1985). If asymptomatic bacteriuria leads to serious complications as functional deterioration of kidney then there is need for screening of asymptomatic bacteriuria in diabetic female (Nicolle 2000). Since due to unavailability of such evidences (Schmaldienst et al. 2002) but not including all (Zhanel et al. 1990a; Patterson and Andriole 1997) believe that there is no justified treatment for asymptomatic bacteriuria. A randomized controlled trial has been conducted in which 108 diabetic women with asymptomatic bacteriuria diagnosed by two urine cultures showing $\geq 105$ colony forming units of an organism per milliliter were randomized to receive a 3 or 14-day course of either co-trimoxazole or placebo (Harding et al. 2002). Patients in group of antibiotic treatment who were infected with resistant microorganism was provided with ciprofloxacin but this study was discontinued due to the occurrence of early relapses in first six patients that were prescribed to an antibiotic regimen of 3-day. Screening of all patients were done after every three months for the detection of bacteriuria. Further suppressive antimicrobial therapy was provided to women confirmed as bacteriuric that were assigned to group of antibiotic therapy. When compared with $20 \%$ of women who received antibiotics, only $78 \%$ of placebo recipients showed bacteriuria following 4 weeks at the end of initial course of therapy. 23 out of 55 women (42\%) in antimicrobial-therapy group and 20 out of 50 women (40\%) in the placebo group had at least one episode of symptomatic urinary tract infections during mean follow-up of 27 months. In placebo and antimicrobial-therapy group, the time to first symptomatic episode was similar as were the rates of hospitalization for urinary tract infections and any symptomatic urinary tract infections which exhibited that treatment of asymptomatic bacteriuria in diabetic women fails to decrease the risk of complications. For the screening and/or treatment of asymptomatic bacteriuria, DM itself should not be considered as an indication (Harding et al. 2002). Infectious Diseases Society of America recommends a 3-day course with co-trimoxazole as standard therapy for uncomplicated acute phase of bacterial cystitis. Alternative treatment can be used in which diabetic patient can be prescribed fluoroquinolone or trimethoprim alone. Other fluoroquinolones also show similar rate of effectiveness but these should only be used as alternative treatment in communities with higher resistance to co-trimoxazole (Warren et al. 1999). For the treatment of complicated lower urinary tract infections, the efficacy of 5-day ofloxacin treatment was compared with 10-day regimen that was performed by double-blind study (Hoepelman et al. 2003). 416 women were included in this study with no confirmed information that how many of them have DM. The authors concluded that both treatments have similar effectiveness (Hoepelman et al. 2003). Another randomized double-blind study which recruited 85 (20\%) women with DM, concluded that 7-day treatment with ciprofloxacin or with ofloxacin resulted in cure rate of $90 \%$ and $87 \%$, respectively (Raz et al. 2000). Cefixime, a third-generation cephalosporin is well absorbed when taken orally and has plasma half-life of 3-4 h, elicits better efficiency against urinary tract infections (Chaudhary et al. 2015). But unfortunately, resistance against cefixime is increased in diabetic patients, suggesting amendments in treatment strategies for urinary tract infections in diabetic patients (Malmartel and Ghasarossian 2016).

\section{Preventive measures}

The need for additional non-antimicrobial strategies is due to increasing problem of resistant uropathogens (Gupta et al. 1999). General advice comprises sufficient intake of fluid, minimum spermicides use, during voiding make sure that the bladder is completely emptied and restrictive use of catheter. Ingestion of cranberry juice is an interesting 
possible preventive measure. At first, it was thought that cranberry juice had beneficial role in the acidification of urine. Recently, it has been recognized that cranberry juice inhibit the adherence of bacteria to the uroepithelial cells and considered as one of most important preventive measure (Raz et al. 2004). Oral or vaginal administration of Lactobacilli is another possible preventive strategy to control urinary tract infections in diabetic conditions. They are thought to protect against urinary tract infections by competitive exclusion of uropathogens and are the part of commensal vaginal flora (Boris et al. 1998). The recurrence of urinary tract infections in women with $E$. coli infection is reduced by a regular drinking of cranberry juice but not of Lactobacillus GG drink (Kontiokari et al. 2001). The recurrence rate of urinary tract infections in postmenopausal women is reduced by the estrogen administration especially if administered vaginally (Hextall 2000). An essential step in the pathogenesis of urinary tract infections is adherence of $E$. coli to uroepithelial cell. Preventive measures would lead to decreased incidence of urinary tract infections. Recently, attention has been diverged towards the vaccine development. This vaccine is based on type 1 fimbriae of E. coli. It has been observed that this vaccine is helpful in decreasing the incidence of urinary tract infections through the inhibition of $E$. coli attachment to uroepithelial cells in monkeys to whom vaccine were provided (Langermann et al. 1997, 2000). It is also demonstrated that decrease in the adherence of type-1 fimbriated E. coli to diabetic uroepithelial cells by addition of vaccine-induced antiserum to uroepithelial cells was occurred that was isolated from diabetic women (Meiland et al. 2001). Although, this vaccine is safe but it proved to be only $30 \%$ effective in young sexually active women, so further clinical studies have been stopped. Bacterial vaginosis, mainly responsible for vaginal discharge in women of reproductive age, also engaged with high recurrence rate. Probiotics are helpful for preventing recurrences of bacterial vaginosis (Parma et al. 2014). Generally, normal vaginal microbiota is dominated by lactobacilli, and strong evidence has suggested negative association between bacterial vaginosis and presence of lactobacilli. Although, some conflicting studies are still present. Yet, most studies have suggested positive outcomes upon supplementation with probiotics (Falagas et al. 2007).

\section{Skin and soft tissue infections in diabetic conditions}

In diabetic individuals, skin and soft tissue infections are leading causes of morbidity and occasionally mortality (DiNubile and Lipsky 2004; Kao et al. 2005; Homer-Vanniasinkam 2007; Sendi et al. 2008). At all anatomic sites, these infections can occur but the most common site is foot and it is frequently affected in diabetic patients (Frykberg et al. 2006). Annually, about 111,000 diabetic persons suffering from foot infections are hospitalized in America. It contributes to nearly $60 \%$ of total lower extremity amputations (Lipsky 2004). Both in ambulatory and hospitalized patients, $S$. aureus is most common pathogen that is present in skin and soft tissues infections (Kirby et al. 2002; Liu et al. 2008; Odell 2010). It is estimated that lifetime risk of developing a foot ulcer is up to $25 \%$ in patients with DM (Singh et al. 2005). Approximately 3\% incidences of diabetic-foot ulcers are reported annually while, in America and United Kingdom, the reported incidences of diabetic-foot ulcers are as high as 10\% (Reiber et al. 1999). Once after the development of foot ulcer, risk of wound progression increases that may finally lead towards amputation. The risk of diabetic ulceration is up to $85 \%$ of the cases that leads to amputation (Reiber et al. 1999).

For the development of diabetic-foot infections, there are several factors that influence the diabetic patients. These factors include immunopathy, neuropathy and vasculopathy. Peripheral neuropathy is considered the most prominent risk factor that occur early in the pathogenesis of diabetic foot infections and also diabetic foot ulcers (Clayton and Elasy 2009). Neuropathy results in diabetic foot ulcers that is more than 60\% (Dyck et al. 1999; Bowering 2001). In diabetic patients, neuropathy is established in sensory, motor and autonomic parts of the nervous system (Bowering 2001). An imbalance between flexion and extension of the affected foot occur as a result of impairment in the innervations of intrinsic muscles of the foot. Abnormal bony prominences and pressure points is due to the abnormalities of anatomic foot that will gradually lead towards ulceration and skin breakdown. A reduction in functionality of sweat and oil gland is due to autonomic neuropathy. So, natural ability of foot to moisturize the overlying skin is lost and skin becomes dry. It also becomes more susceptible to tears and it will subsequently lead towards the development of infection. The loss of sensation impairs the development of ulcerations. Patients are often unable to detect their lower extremities as trauma occurs at the affected site. Many wounds go unnoticed because of this and gradually become worst.

\section{Microbiology of skin and soft tissue infections in diabetic conditions}

The skin and mucous membranes of diabetic patients have certain common bacterial and fungal pathogens, such as Candida albicans and S. aureus. Pathogenic bacteria that may predispose susceptible patient to lower extremity infection is found to colonize in diabetic foot ulcerations. According to a study of 84 randomly selected hospitalized patients with severe diabetic foot infections, $83 \%$ of cultures demonstrated that existence of polymicrobial flora with an 
average of 2.8 species per specimen and ratio of aerobic to anaerobic bacteria is 3:1 (Hobizal and Wukich 2012). Staphylococcus epidermidis, S. aureus, and Streptococcus species were the most frequently isolated organisms. Peptostreptococcus magnus and Bacteroides fragilis were observed among anaerobes (Calhoun et al. 2002). In various studies, it is found that the most common organisms were aerobic gram-positive cocci isolated from the wounds of diabetic patients, especially diabetic foot infections. Staphylococcus aureus, Enterococcus, facultative gram-negative bacilli, and group B streptococci are most commonly identified pathogens in the cultures of limb-threatening infections.

\section{Treatment strategies for skin and soft tissue infections in diabetic conditions}

\section{Preventive measures}

For the treatment of diabetic foot infections, there is a formulated guidelines and key recommendations provided by infectious diseases society of America. According to these guidelines, it is stated that an empirical treatment of antimicrobial agents should be applied on the basis of likely pathologic agents and infection severity (Lipsky et al. 2006). Antimicrobial agent is more active against gram-positive cocci with special attention for methicillin-resistant Staphylococcus aureus which are included in the antibiotic treatment. Extended coverage for gram-negative bacilli and enterococcus species included in the previously treated or severe diabetic foot infections. Anti-anaerobic therapy is required for foul smelling and gangrenous wounds. In the selection of treatment program as well as concerned side effects of potential drug, bioavailability, pharmacokinetics, route of administration and frequency are all important factors and have their role in the cost of therapy (McKinnon et al. 1997). It has been reported that patients treated with ertapenem have clinical and microbiological outcomes that were equivalent to those treated with piperacillin/tazobactam (Singh et al. 2005). This study recommends that dose of ertapenem that is given once a daily is beneficial in setting of diabetic foot infections, although the fact about the ertapenem is unable to provide protection from most of $P$. aeruginosa or enterococci. It also indicates that in polymicrobial diabetic foot infections, these organisms may only be contaminants. Based upon clinical studies, the duration of antibiotic therapy that is considered an optimal duration has yet to be properly defined. In general, treatment of mild and severe diabetic foot infections started from 2-4 weeks of antibiotic therapy and route of administration is intravenous and another is started from 4-6 weeks of antibiotic therapy. Another way for the control of moderate to severe diabetic foot infection, is the surgical management and it includes drainage, debridement of non-viable soft tissue and bone and aggressive incision. Modern approach is to use adjunctive therapies which include application of negative pressure wound therapy, hyperbaric oxygen treatment and use of antibiotic impregnated beads (Armstrong and Lavery 2005; Krause et al. 2009; Chen et al. 2010). The role of antibiotics remains unclear for the treatment of foot ulcers in patients with DM (Lipsky et al. 2004). However, a high priority for the management of infected diabetic foot as part of multidisciplinary care (Reiber and Raugi 2005) is revascularization (van Baal 2004). The roles of adjunctive therapies are yet to be established (Cavanagh et al. 2005).

\section{Treatment strategies}

It is recommended that regular foot inspection and adequate footwear are important measures that should be taken by diabetic patients to control diabetic foot infections (Robson et al. 1998; Boulton et al. 1999; Foot 2007). However, the majority of diabetic patients do not care their feet and or regular inspections of their feet (Uccioli et al. 1995; Robson et al. 1998; Boulton et al. 1999). These studies indicate that strategies including regular inspection and examination of feet and footwear, identification of high risk patient, education of patient, family and health care staff, use of appropriate footwear, and treatment of nonulcerative pathology can increase the awareness of the problem and aptitude for self-management and ability to decrease the incidence of minor foot lesions. Several studies have reported that combination of chiropodist care and other strategies reduce the prevalence of non-ulcer pathology (Litzelman et al. 1993, 1997; Rönnemaa et al. 1997). Proper treatment of callosities, cracked skin, dry skin and nail deformities is essential and specific skills are required (Boulton et al. 1999). A study conducted in Sweden has found that only a few chiropodists had a close cooperation with the health care system, and only $14-22 \%$ had any kind of education with regard to diabetic foot (Apelqvist et al. 2000). In a cross-sectional population-based study, $80 \%$ of diabetic individuals older than 25 years claimed to have access to chiropodist (Gottrup 2004). A number of studies have shown that such footwear, when available and used, can prevent re-ulceration in patients with previous foot ulcers (Edmonds et al. 1986; Chantelau et al. 1990; Breuer 1994; Chantelau and Haage 1994; Mueller 1997).

\section{Respiratory tract infections in diabetic conditions}

Increased hospitalizations in diabetic individuals as compared to those without diabetes are the most important cause of respiratory tract infections. Bacterial, fungal and viral are the most common etiological factors in diabetic patients 
(Kornum et al. 2007; Peleg et al. 2007; Casqueiro et al. 2012a). Lung inflammation that occurs in about $48 \mathrm{~h}$ after admission of patient in hospital is hospital-acquired pneumonia. Hospital-acquired pneumonia is a group of diseases that refers to pneumonia infections and linked with mechanical lung ventilation. It is an inflammation that occurs at about $48-72 \mathrm{~h}$ of ventilation in patients, as well as pneumonia that makes an association with exposure to pathogens associated with health care. The incidence is estimated to be 5-15 cases per 1000 hospitalizations in European countries with estimated rate of mortality of 30-50\% (Fleming et al. 1991). However, the percentage of diabetic patients hospitalized with community-acquired pneumonia was $<5 \%$ which is similar to the frequency of diabetes in several communities (Woodhead et al. 1987). Similarly, in another study, a higher mortality was observed among diabetic patients in a meta-analysis of 33,000 patients with community-acquired pneumonia (Fine et al. 1996). In diabetic individuals, the main reason for pneumococcal pneumonia is bacteremia (Watanakunakorn and Bailey 1997; Kalin et al. 2000) but the death rate with pneumococcal pneumonia in diabetic condition was found to be similar to that of pneumococcal pneumonia in non-diabetic patients (Thomsen et al. 2004). However, during influenza epidemics, the adverse effect of DM on the rate of morbidity and mortality has long been identified (Barker and Mullooly 1982). During influenza epidemics, the risk of hospitalization is sixfold higher in diabetic patients than that non-diabetic individuals (Diepersloot et al. 1987) but the high prevalence of co-morbid conditions, such as cardiac failure and metabolic compromise are also important (Finelli et al. 2008). The mortality rate of diabetic patients with pulmonary tuberculosis approaches to $50 \%$ (Casqueiro et al. 2012a). The increased susceptibility to tuberculosis in diabetic patients may be due to the impairment of immune functions (Restrepo and Schlesinger 2013). Pulmonary tuberculosis still poses a potential threat to diabetic individuals. According to an investigation done by a Japanese study that over 6-year period, $13.2 \%$ patients hospitalized with tuberculosis were identified with DM (Yamagishi et al. 1996).

\section{Bacteriology of respiratory tract infections in diabetic conditions}

The type of organisms that are responsible for communityacquired pneumonia in diabetic patients vary from that of non-diabetic individuals, with an increased prevalence of Gram-negative bacteria such as K. pneumoniae and $S$. aureus [81]. Most important causative organism that are responsible for the occurrence of respiratory tract infections -associated with DM are S. pneumoniae and influenza virus (Arancibia et al. 2014). It has been expected that in diabetic patients, the cases of fungal infections that are caused by Mucorales are 50-75\% while predisposing factor is acidosis. For onychomycosis in diabetic patients, the second responsible microorganism is Aspergillus (Jones 2010). It has been found that during the first four days of hospitalization, the most common bacteria causing hospital-acquired pneumonia are S. pneumoniae, Enterobacter, K. pneumoniae, Serratia, E. coli, S. aureus (methicillin-susceptible), Proteus and Haemophilus influenzae (Zhang et al. 2014; Klekotka et al. 2015). The predominance of bacteria from the 5 th day of hospitalization include Acinetobacter spp., Staphylococcus aureus (methicillin-resistant MRSA), E. coli, L. pneumophila, Pseudomonas aeruginosa, and K. pneumoniae (Klekotka et al. 2015). In European countries and America, S. aureus is most commonly isolated bacteria associated with hospitalacquired pneumonia (Jones 2010b).

\section{Antimicrobial resistance in respiratory tract infections in diabetic conditions}

Klebsiella pneumoniae showed resistance to fosfomycin ( $26.7 \%$ vs $37.6 \%)$ and sulfamethoxazole ( $22.7 \%$ vs $32.5 \%)$ in pneumonia among diabetic patients. In intensive care unit, resistance rates of $K$. pneumoniae have been reported to be significantly lower in diabetic patients than that in nondiabetic individuals against fosfomycin $(42.6 \%$ vs $62.6 \%)$ aztreonam (53.4\% vs $69.5 \%)$, tobramycin ( $42.5 \%$ vs $61.0 \%$ ), meropenem ( $37.7 \%$ vs $59.8 \%$ ), amikacin ( $37.8 \%$ vs $52.8 \%$ ) and cefotetan (45.2\% vs $63.2 \%)$. Only sulfamethoxazole
Table 2 Pooled estimates of association of diabetes mellitus with surgical site infections. Adopted from (Martin et al. 2016)

\begin{tabular}{llllr}
\hline Surgery type & No. of studies & Pooled estimate & $\begin{array}{l}\text { 95\% prediction } \\
\text { interval }\end{array}$ & $I^{2}$ or \% \\
\hline Gynecological & 6 & 1.61 & $1.15-2.24$ & 4.0 \\
Colorectal & 7 & 1.16 & $0.93-1.44$ & 9.5 \\
Arthroplasty & 6 & 1.26 & $1.01-1.66$ & 11.7 \\
Breast & 5 & 1.58 & $0.91-2.72$ & 2.7 \\
Cardiac & 15 & 2.03 & $1.13-4.05$ & 22.4 \\
Spinal & 14 & 1.66 & $1.10-2.32$ & 8.1 \\
$\begin{array}{l}\text { Other/Multiple surgery } \\
\text { types combined }\end{array}$ & 37 & 1.46 & $1.07-2.00$ & 41.5 \\
\hline
\end{tabular}




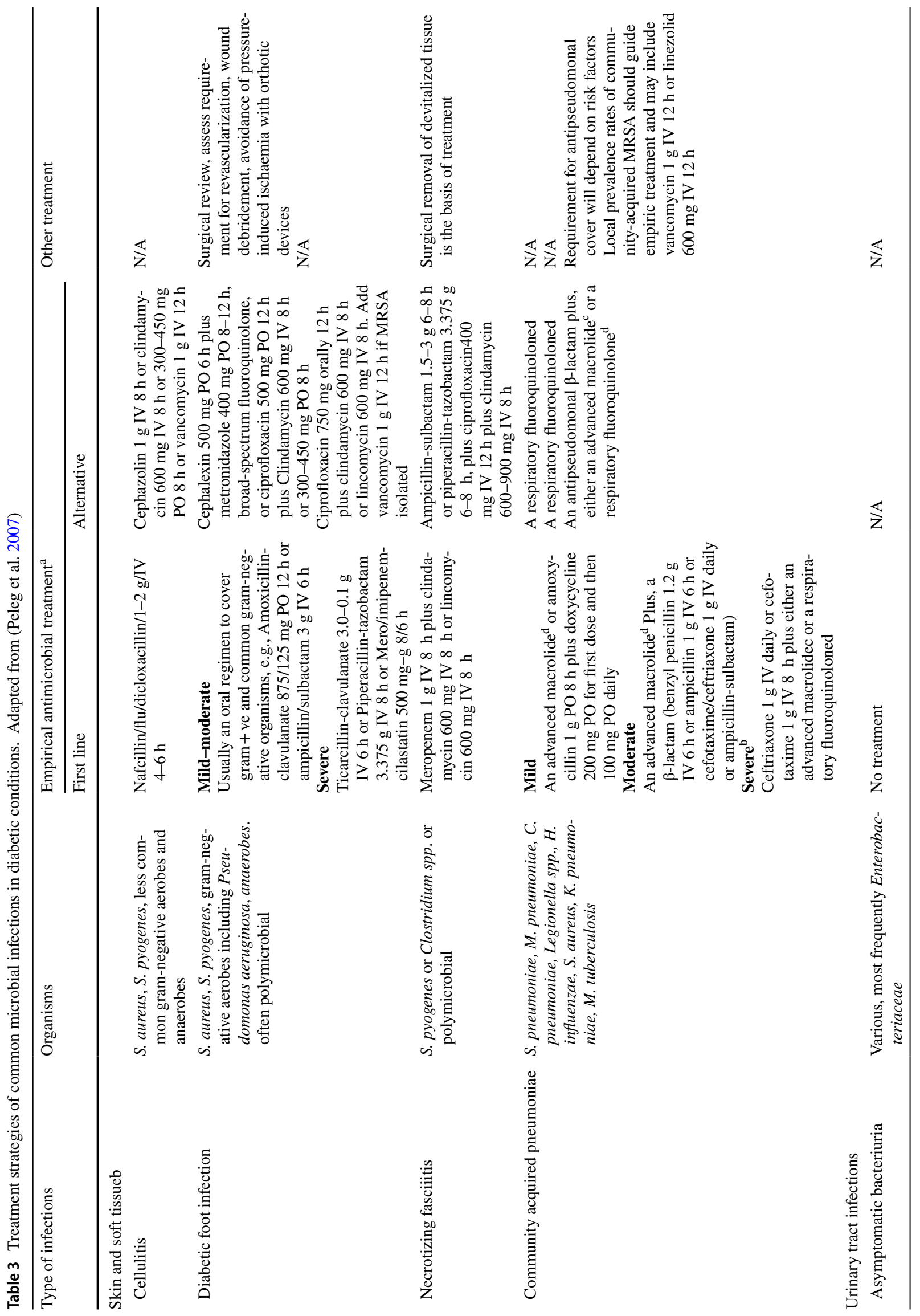




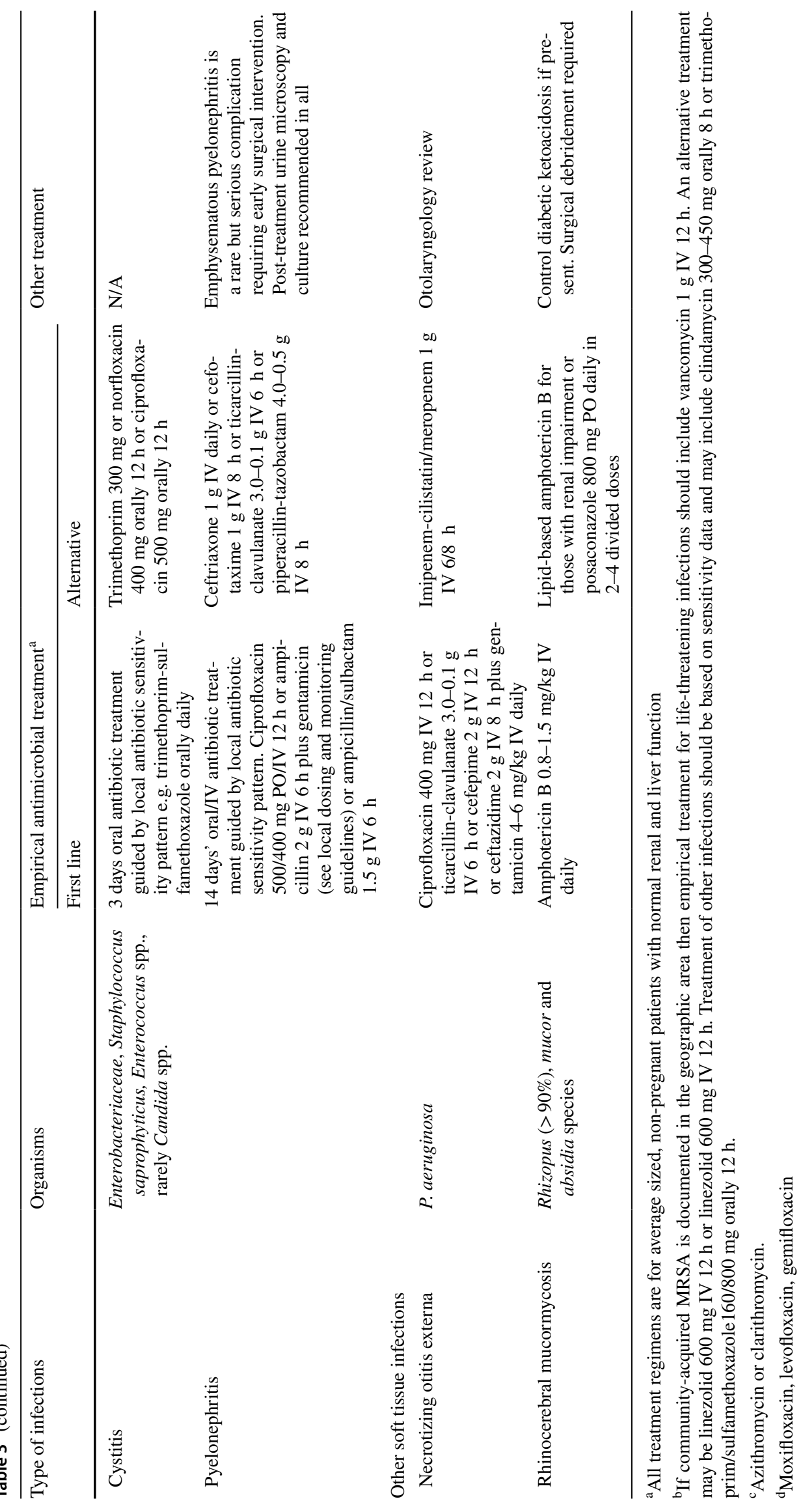


exhibited a low resistance (13.8\% vs $25.6 \%$ ) in non-intensive care unit. Those with a higher HbA1c level showed significantly lower resistance to sulperazone ( $11.7 \%$ vs $40.0 \%$ ) and fosfomycin (14.3\% vs $66.7 \%$ ) when compared with diabetic individuals having $\mathrm{HbA} 1 \mathrm{c}<6.5 \%$.

\section{Treatment strategies for respiratory tract infections in diabetic conditions}

There are no known effective treatment strategies for respiratory tract infections in diabetic conditions. It has been reported that diabetic subjects having respiratory tract infections, respond appropriately to anti-tuberculous treatment (Kameda et al. 1990).

\section{Surgical site infections in diabetic conditions}

In United States, prevalence of DM is increasing day-byday (Cheng et al. 2013) and nowadays, it has become an important that there should be an appropriate control and management of patients with DM to make possible prevention from infections-associated with hospital. It has been found that DM influence the surgical site infections and influence of hyperglycemia on surgical site infections has also been confirmed (Zimlichman et al. 2013). A total of 90 studies provided the estimates for the association between DM and surgical site infections have been summarized in Table 2 (Martin et al. 2016). Among the patients undergoing cardiac surgery, the actual pooled estimate was found highest. Mostly, diabetic patients do not survive long due to increase development of antimicrobial resistance against infections. This has been found that increased risk of surgical site infections was consistent across surgery types among diabetic patients except the gynecological and obstetrical surgery (Mu et al. 2011). It has been reported that glucose levels remain consistently higher in diabetic patients with surgical site infections receiving colorectal resection when compared with uninfected diabetic patients (Sehgal et al. 2011). Increased rates of infection in colorectal and bariatric surgery,(Kwon et al. 2013) orthopaedic spine surgery (Caputo et al. 2013) and cardiac surgery (Zerr et al. 1997; Furnary et al. 1999; Wilson and Sexton 2003) has been found to be associated with raised blood glucose level (Hardy et al. 2010; Jeon et al. 2012).

\section{Treatment strategies}

There are no known possible and effective treatment strategies for surgical site infection associated with DM. In Table 3, we have summarized the infections associated with DM and their possible treatment strategies (Peleg et al.
2007). The rates of morbidity and mortality increase due to these infections.

\section{Conclusion}

The aforementioned convincingly evidences strongly suggest the utmost need of appropriate hygiene conditions for diabetic patients in hospitals. Subsequently, such a palliative strategy can prophylactically secure future complication of antimicrobial resistance in diabetic patients. As it is better to spend one once on prevention then two once on treatment because the normal treatment regimen is ineffective against diabetic patients suffering from microbial infections in contrast to non-diabetics. Thus, radical amendments in hospital diabetic wards such as by providing them isolated and hygienic conditions can ultimately, subsides the consequences of antimicrobial resistance in diabetic patients. Additionally, further well-designed and randomized studies are required for accessing the significance of hygienic conditions and possibly expected favorable outcomes. Surely, such types of studies will also helpful for better understanding of radiological, laboratory as well as clinical characteristics of infections affiliated with diabetic patients. Furthermore, this study also urges policy makers to formulate an antimicrobial policy for diabetics for rational use of antibiotics.

Acknowledgements This work was financially supported by the research Grants (5661/Punjab/NRPU/R\&D/HEC/2016, 6429/Punjab/ NRPU/R\&D/HEC/2016 and 8365/Punjab/NRPU/R\&D/HEC/2017) received from Higher Education Commission (HEC) of Pakistan.

\section{Compliance with ethical standards}

Conflict of interest Authors declare that they do not have conflict of interest for this article.

\section{References}

Apelqvist J, Bakker K, Van Houtum WH, Nabuurs-Franssen MH, Schaper NC (2000) International consensus and practical guidelines on the management and the prevention of the diabetic foot. Diabetes Metab Res Rev 16:S84-S92

Arancibia F et al (2014) Importance of Legionella pneumophila in the etiology of severe community-acquired pneumonia in Santiago, Chile. Chest 145:290-296

Armstrong DG, Lavery LA (2005) Negative pressure wound therapy after partial diabetic foot amputation: a multicentre, randomised controlled trial. Lancet 366:1704-1710

Barker WH, Mullooly JP (1982) Pneumonia and influenza deaths during epidemics: implications for prevention. Arch Intern Med 142:85-89

Barnett BJ, Stephens DS (1997) Urinary tract infection: an overview. Am J Med Sci 314:245-249 
Boris S, Suárez JE, Vázquez F, Barbés C (1998) Adherence of human vaginal lactobacilli to vaginal epithelial cells and interaction with uropathogens. Infect Immun 66:1985-1989

Boulton AJ, Meneses P, Ennis WJ (1999) Diabetic foot ulcers: a framework for prevention and care. Wound Repair Regen 7:7-16

Bowering CK (2001) Diabetic foot ulcers. Pathophysiology, assessment, and therapy. Can Fam Physician 47:1007-1016

Boyko EJ, Fihn SD, Scholes D, Abraham L, Monsey B (2005) Risk of urinary tract infection and asymptomatic bacteriuria among diabetic and nondiabetic postmenopausal women. Am J Epidemiol 161:557-564

Breuer U (1994) Diabetic patient's compliance with bespoke footwear after healing of neuropathic foot ulcers. Diabete Metab 20:415-419

Brown JS et al (2005) Urologic complications of diabetes. Diabetes Care 28:177-185

Calhoun JH, Overgaard KA, Stevens CM, Dowling JP, Mader JT (2002) Diabetic foot ulcers and infections: current concepts. Adv Skin Wound Care 15:31-42

Calliari LE, Almeida FJ, Noronha RM (2019) Infections in children with diabetes. J Pediatr (Rio J). https://doi.org/10.1016/j. jped.2019.1009.1004

Caputo AM, Dobbertien RP, Ferranti JM, Brown CR, Michael KW, Richardson WJ (2013) Risk factors for infection after orthopaedic spine surgery at a high-volume institution. J Surg Orthop Adv 22:295-298

Carton JA, Maradona JA, Nuno FJ, Fernandez-Alvarez R, Perez-Gonzalez F, Asensi V (1992) Diabetes mellitus and bacteraemia: a comparative study between diabetic and non-diabetic patients. Eur J Med 1:281-287

Casqueiro J, Casqueiro J, Alves C (2012a) Infections in patients with diabetes mellitus: a review of pathogenesis. Indian J Endocrinol Metab 16:S27-36

Casqueiro J, Casqueiro J, Alves C (2012b) Infections in patients with diabetes mellitus: a review of pathogenesis. Indian J Endocrinol Metab 16(Suppl 1):S27-36. https://doi. org/10.4103/2230-8210.94253

Cavanagh PR, Lipsky BA, Bradbury AW, Botek G (2005) Treatment for diabetic foot ulcers. Lancet 366:1725-1735

Chantelau E, Haage P (1994) An audit of cushioned diabetic footwear: relation to patient compliance. Diabet Med 11:114-116

Chantelau E, Kushner T, Spraul M (1990) How effective is cushioned therapeutic footwear in protecting diabetic feet? A clinical study. Diabet Med 7:355-359

Chaudhary MK, Pandey G, Godar M, Gautam R, Gurung S (2015) Efficacy of cefixime in the treatment of urinary tract infection. World J Pharm Pharm Sci 4:987-994

Chen CE, Ko JY, Fong CY, Juhn RJ (2010) Treatment of diabetic foot infection with hyperbaric oxygen therapy. Foot Ankle Surg 16:91-95

Cheng YJ et al (2013) Secular changes in the age-specific prevalence of diabetes among US adults: 1988-2010. Diabetes Care 36:2690-2696

Clayton W, Elasy TA (2009) A review of the pathophysiology, classification, and treatment of foot ulcers in diabetic patients. Clin Diabetes 27:52-58

Cook DJ, Achong MR, Dobranowski J (1989) Emphysematous pyelonephritis: complicated urinary tract infection in diabetes. Diabetes Care 12:229-232

Diepersloot RJA, Bouter KP, Beyer WEP, Hoekstra JBL, Masurel N (1987) Humoral immune response and delayed type hypersensitivity to influenza vaccine in patients with diabetes mellitus. Diabetologia 30:397-401

DiNubile MJ, Lipsky BA (2004) Complicated infections of skin and skin structures: when the infection is more than skin deep. J Antimicrob Chemother 53:37-50
Dyck PJ, Davies JL, Wilson DM, Melton L, O’Brien P (1999) Risk factors for severity of diabetic polyneuropathy. Diabetes Care 22:1479-1486

Edmonds ME, Blundell MP, Morris ME, Thomas EM, Cotton LT, Watkins PJ (1986) Improved survival of the diabetic foot: the role of a specialised foot clinic. Q J Med 60:763-771

Falagas M, Betsi GI, Athanasiou S (2007) Probiotics for the treatment of women with bacterial vaginosis. Clin Microbiol Infect 13:657-664. https://doi.org/10.1111/j.1469-0691.2007.01688.x

Fine MJ et al (1996) Prognosis and outcomes of patients with community-acquired pneumonia: a meta-analysis. JAMA 275:134-141

Finelli L et al (2008) Influenza-associated pediatric mortality in the United States: increase of Staphylococcus aureus coinfection. Pediatrics 122:805-811

Fleming DM, Crombie DL, Cross KW (1991) Disease concurrence in diabetes mellitus: a study of concurrent morbidity over 12 months using diabetes mellitus as an example. J Epidemiol Community Health 45:73-77

Foot IWGotD (2007) International consensus on the diabetic foot. International Working Group on the Diabetic Foot

Forland M, Thomas VL (1985) The treatment of urinary tract infections in women with diabetes mellitus. Diabetes Care 8:499-506

Forland M, Thomas V, Shelokov A (1977) Urinary tract infections in patients with diabetes mellitus: studies on antibody coating of bacteria. JAMA 238:1924-1926

Frykberg RG et al (2006) Diabetic foot disorders: a clinical practice guideline (2006 revision). J Foot Ankle Surg 45:S1-S66

Fu AZ, Iglay K, Qiu Y, Engel S, Shankar R, Brodovicz K (2014) Risk characterization for urinary tract infections in subjects with newly diagnosed type 2 diabetes. J Diabetes Complicat 28:805810. https://doi.org/10.1016/j.jdiacomp.2014.06.009

Furnary AP, Zerr KJ, Grunkemeier GL, Starr A (1999) Continuous intravenous insulin infusion reduces the incidence of deep sternal wound infection in diabetic patients after cardiac surgical procedures. Ann Thorac Surg 67:352-360

Gottrup F (2004) A specialized wound-healing center concept: importance of a multidisciplinary department structure and surgical treatment facilities in the treatment of chronic wounds. Am J Surg 187:S38-S43

Gupta K, Scholes D, Stamm WE (1999) Increasing prevalence of antimicrobial resistance among uropathogens causing acute uncomplicated cystitis in women. JAMA 281:736-738

Hakeem LM, Bhattacharyya DN, Lafong C, Janjua KS, Serhan JT, Campbell IW (2009) Diversity and complexity of urinary tract infection in diabetes mellitus. Br J Diabetes Vasc Dis 9:119-125

Harding GK, Zhanel GG, Nicolle LE, Cheang M (2002) Antimicrobial treatment in diabetic women with asymptomatic bacteriuria. $\mathrm{N}$ Engl J Med 347:1576-1583

Hardy SJ, Nowacki AS, Bertin M, Weil RJ (2010) Absence of an association between glucose levels and surgical site infections in patients undergoing craniotomies for brain tumors. J Neurosurg 113:161-166

Hextall A (2000) Oestrogens and lower urinary tract function. Maturitas 36:83-92

Hobizal KB, Wukich DK (2012) Diabetic foot infections: current concept review. Diabet Foot Ankle 3:18409

Hoepelman AI, Meiland R, Geerlings SE (2003) Pathogenesis and management of bacterial urinary tract infections in adult patients with diabetes mellitus. Int J Antimicrob Agents 22:35-43

Homer-Vanniasinkam S (2007) Surgical site and vascular infections: treatment and prophylaxis. Int J Infect Dis 11:S17-S22

Jeon CY, Furuya EY, Berman MF, Larson EL (2012) The role of preoperative and post-operative glucose control in surgical-site infections and mortality. PLoS ONE 7:e45616

Johnson JR, Stamm WE (1989) Urinary tract infections in women: diagnosis and treatment. Ann Intern Med 111:906-917 
Jones RN (2010) Microbial etiologies of hospital-acquired bacterial pneumonia and ventilator-associated bacterial pneumonia. Clin Infect Dis 51:S81-S87

Joshi N, Caputo GM, Weitekamp MR, Karchmer A (1999) Infections in patients with diabetes mellitus. N Engl J Med 341:1906-1912

Kalin M et al (2000) Prospective study of prognostic factors in community-acquired bacteremic pneumococcal disease in five countries. J Infect Dis 182:840-847

Kameda K, Kawabata S, Masuda N (1990) Follow-up study of short course chemotherapy for pulmonary tuberculosis complicated with diabetes mellitus. Kekkaku 65:791-803

Kao LS, Knight MT, Lally KP, Mercer DW (2005) The impact of diabetes in patients with necrotizing soft tissue infections. Surg Infect 6:427-438

Kirby JT, Mutnick AH, Jones RN, Biedenbach DJ, Pfaller MA, Group SP (2002) Geographic variations in garenoxacin (BMS284756) activity tested against pathogens associated with skin and soft tissue infections: report from the SENTRY antimicrobial surveillance program (2000). Diagn Microbiol Infect Dis 43:303-309

Klekotka RB, Mizgała E, Król W (2015) The etiology of lower respiratory tract infections in people with diabetes. Pneumonol Alergol Pol 83:401-408

Kofteridis DP et al (2009) Effect of diabetes mellitus on the clinical and microbiological features of hospitalized elderly patients with acute pyelonephritis. J Am Geriatr Soc 57:2125-2128

Kontiokari T, Sundqvist K, Nuutinen M, Pokka T, Koskela M, Uhari M (2001) Randomised trial of cranberry-lingonberry juice and Lactobacillus $G G$ drink for the prevention of urinary tract infections in women. BMJ 322:1571

Kornum JB, Thomsen RW, Riis A, Lervang H-H, Schønheyder HC, Sørensen HT (2007) Type 2 diabetes and pneumonia outcomes: a population-based cohort study. Diabetes Care 30:2251-2257

Krause FG, deVries G, Meakin C, Kalla TP, Younger AS (2009) Outcome of transmetatarsal amputations in diabetics using antibiotic beads. Foot Ankle Int 30:486-493

Kwon S, Thompson R, Dellinger P, Yanez D, Farrohki E, Flum D (2013) Importance of perioperative glycemic control in general surgery: a report from the surgical care and outcomes assessment program. Ann Surg 257:8-14

Langermann S et al (1997) Prevention of mucosal Escherichia coli infection by $F i m H$-adhesin-based systemic vaccination. Science 276:607-611

Langermann S et al (2000) Vaccination with fimh adhesin protects cynomolgus monkeys from colonization and infection by uropathogenic Eschevichia coli. J Infect Dis 181:774-778

Laupland K, Ross T, Pitout J, Church D, Gregson D (2007) Community-onset urinary tract infections: a population-based assessment. Infection 35:150-153

Lipsky BA (2004a) Medical treatment of diabetic foot infections. Clin Infect Dis 39:S104-114

Lipsky BA et al (2004b) Diagnosis and treatment of diabetic foot infections. Clin Infect Dis 39:885-910

Lipsky B et al (2006) Infectious diseases society of America: diagnosis and treatment of diabetic foot infections. Plast Reconstr Surg 117:212S-238S

Litzelman DK et al (1993) Reduction of lower extremity clinical abnormalities in patients with non-insulin-dependent diabetes mellitus: a randomized, controlled trial. Ann Intern Med 119:36-41

Litzelman DK, Marriott DJ, Vinicor F (1997) The role of footwear in the prevention of foot lesions in patients with NIDDM: conventional wisdom or evidence-based practice? Diabetes Care 20:156-162

Liu C et al (2008) A population-based study of the incidence and molecular epidemiology of methicillin-resistant Staphylococcus aureus disease in San Francisco, 2004-2005. Clin Infect Dis 46:1637-1646
Lye W, Chan R, Lee E, Kumarasinghe G (1992) Urinary tract infections in patients with diabetes mellitus. J Infect 24:169-174

Malmartel A, Ghasarossian C (2016) Bacterial resistance in urinary tract infections in patients with diabetes matched with patients without diabetes. J Diabetes Complicat 30:705-709. https:// doi.org/10.1016/j.jdiacomp.2016.01.005

Martin ET et al (2016) Diabetes and risk of surgical site infection: a systematic review and meta-analysis. Infect Control Hosp Epidemiol 37:88-99

Matusda M, De Fronzo R (1999) Insulin sensitivity indices obtained from oral glucose tolerance testing. Diabetes Care 22:1462-1470

McKinnon PS, Paladino JA, Grayson ML, Gibbons GW, Karchmer AW (1997) Cost-effectiveness of ampicillin/sulbactam versus imipenem/cilastatin in the treatment of limb-threatening foot infections in diabetic patients. Clin Infect Dis 24:57-63

Meiland R, Geerlings S, Brouwer E (2001) Adherence of Escherichia coli to uroepithelial cells of women with diabetes mellitus (DM) can be inhibited by vaccine-induced anti-Fim CH antiserum [abstract no. L1349]. In: Proceedings of the 41th Interscience Congres on Antimicrobial Agents and Chemotherapy, pp 16-19

Meiland R, Geerlings S, De Neeling A, Hoepelman A (2004) Diabetes mellitus in itself is not a risk factor for antibiotic resistance in Escherichia coli isolated from patients with bacteriuria. Diabet Med 21:1032-1034

Mnif MF et al (2013) Complicated urinary tract infections associated with diabetes mellitus: pathogenesis, diagnosis and management. Indian J Endocrinol Metab 17:442-445

Mu Y, Edwards JR, Horan TC, Berrios-Torres SI, Fridkin SK (2011) Improving risk-adjusted measures of surgical site infection for the National Healthcare Safely Network. Infect Control Hosp Epidemiol 32:970-986

Mueller MJ (1997) Therapeutic footwear helps protect the diabetic foot. J Am Podiatr Med Assoc 87:360-364

Muller L et al (2005) Increased risk of common infections in patients with type 1 and type 2 diabetes mellitus. Clin Infect Dis $41: 281-288$

Nicolle LE (2000) Asymptomatic bacteriuria in diabetic women. Diabetes Care 23:722-723

Nicolle LE (2001) A practical guide to antimicrobial management of complicated urinary tract infection. Drugs Aging 18:243-254

Nicolle L, Friesen D, Harding G, Roos L (1996) Hospitalization for acute pyelonephritis in Manitoba, Canada, during the period from 1989 to 1992: impact of diabetes, pregnancy, and aboriginal origin. Clin Infect Dis 22:1051-1056

Noor S, Zubair M, Ahmad J (2015) Diabetic foot ulcer-a review on pathophysiology, classification and microbial etiology. Diabetes Metab Syndr 9:192-199

Odell CA (2010) Community-associated methicillin-resistant Staphylococcus aureus (CA-MRSA) skin infections. Curr Opin Pediatr 22:273-277

Parma M, Stella Vanni V, Bertini M, Candiani M (2014) Probiotics in the prevention of recurrences of bacterial vaginosis. Altern Ther Health Med 20(Suppl 1):52-57

Patterson JE, Andriole VT (1997) Bacterial urinary tract infections in diabetes. Infect Dis Clin N Am 11:735-750

Peleg AY, Weerarathna T, McCarthy JS, Davis TME (2007) Common infections in diabetes: pathogenesis, management and relationship to glycaemic control. Diabetes Metab Res Rev 23:3-13

Raz R (2003) Asymptomatic bacteriuria. Clinical significance and management. Int J Antimicrob Agents 22:45-47

Raz R et al (2000) Ciprofloxacin 250 mg twice daily versus ofloxacin $200 \mathrm{mg}$ twice daily in the treatment of complicated urinary tract infections in women. Eur J Clin Microbiol Infect Dis 19:327-331

Raz R, Chazan B, Dan M (2004) Cranberry juice and urinary tract infection. Clin Infect Dis 38:1413-1419 
Reiber GE, Raugi GJ (2005) Preventing foot ulcers and amputations in diabetes. Lancet 366:1676-1677

Reiber GE et al (1999) Causal pathways for incident lower-extremity ulcers in patients with diabetes from two settings. Diabetes Care 22:157-162

Restrepo BI, Schlesinger LS (2013) Host-pathogen interactions in tuberculosis patients with type 2 diabetes mellitus. Tuberculosis 93:S10-14

Ribera M, Pascual R, Orozco D, Barba CP, Pedrera V, Gil V (2006) Incidence and risk factors associated with urinary tract infection in diabetic patients with and without asymptomatic bacteriuria. Eur J Clin Microbiol Infect Dis 25:389-393

Robson MC, Mustoe TA, Hunt TK (1998) The future of recombinant growth factors in wound healing. Am J Surg 176:80S-82S

Rönnemaa T, Hämäläinen H, Toikka T, Liukkonen I (1997) Evaluation of the impact of podiatrist care in the primary prevention of foot problems in diabetic subjects. Diabetes Care 20:1833-1837

Schmaldienst S, Dittrich E, Hörl WH (2002) Urinary tract infections after renal transplantation. Curr Opin Urol 12:125-130

Sehgal R et al (2011) Risk factors for surgical site infections after colorectal resection in diabetic patients. J Am Coll Surg 212:29-34

Sendi P, Johansson L, Norrby-Teglund A (2008) Invasive group B streptococcal disease in non-pregnant adults. Infection 36:100-111

Shah BR, Hux JE (2003) Quantifying the risk of infectious diseases for people with diabetes. Diabetes Care 26:510-513

Simonsen JR et al (2015) Bacterial infections in patients with type 1 diabetes: a 14-year follow-up study. BMJ Open Diabetes Res Care 3:e000067. https://doi.org/10.1136/bmjdrc-2014-000067

Singh N, Armstrong DG, Lipsky BA (2005) Preventing foot ulcers in patients with diabetes. JAMA 293:217-228

Steinke D, Seaton R, Phillips G, MacDonald T, Davey P (1999) Factors associated with trimethoprim-resistant bacteria isolated from urine samples. J Antimicrob Chemother 43:841-843

Thomsen RW, Hundborg HH, Lervang H-H, Johnsen SP, Sørensen HT, Schønheyder HC (2004) Diabetes and outcome of communityacquired pneumococcal bacteremia: a 10-year population-based cohort study. Diabetes Care 27:70-76

Uccioli L et al (1995) Manufactured shoes in the prevention of diabetic foot ulcers. Diabetes Care 18:1376-1378

van Baal JG (2004) Surgical treatment of the infected diabetic foot. Clin Infect Dis 39:S123-128

Warren JW, Abrutyn E, Hebel JR, Johnson JR, Schaeffer AJ, Stamm WE (1999) Guidelines for antimicrobial treatment of uncomplicated acute bacterial cystitis and acute pyelonephritis in women. Clin Infect Dis 29:745-759

Watanakunakorn C, Bailey TA (1997) Adult bacteremic pneumococcal pneumonia in a community teaching hospital, 1992-1996n: a detailed analysis of 108 cases. Arch Intern Med 157:1965-1971
Wheat LJ (1980) Infection and diabetes mellitus. Diabetes Care 3:187-197

Wilson SJ, Sexton DJ (2003) Elevated preoperative fasting serum glucose levels increase the risk of postoperative mediastinitis in patients undergoing open heart surgery. Infect Control Hosp Epidemiol 24:776-778

Woodhead M, Macfarlane J, McCracken J, Rose D, Finch R (1987) Prospective study of the aetiology and outcome of pneumonia in the community. Lancet 329:671-674

Wright SW, Wrenn KD, Haynes ML (1999) Trimethoprim-sulfamethoxazole resistance among urinary coliform isolates. J Gen Intern Med 14:606-609

Yamagishi F, Suzuki K, Sasaki Y, Saitoh M, Izumizaki M, Koizumi K (1996) Prevalence of coexisting diabetes mellitus among patients with active pulmonary tuberculosis. Kekkaku 71:569-572

Yu S et al (2014) Disease burden of urinary tract infections among type 2 diabetes mellitus patients in the US. J Diabetes Complicat 28:621-626

Zerr KJ, Furnary AP, Grunkemeier GL, Bookin S, Kanhere V, Starr A (1997) Glucose control lowers the risk of wound infection in diabetics after open heart operations. Ann Thorac Surg 63:356-361

Zhanel GG, Harding GKM, Guay DRP (1990a) Asymptomatic bacteriuria: which patients should be treated? Arch Intern Med 150:1389-1396

Zhanel GG, Harding GKM, Nicolle LE (1990b) Asymptomatic bacteriuria in patients with diabetes mellitus. Rev Infect Dis 13:150-154

Zhanel GG, Nicolle LE, Harding GKM (1995) Prevalence of asymptomatic bacteriuria and associated host factors in women with diabetes mellitus. Clin Infect Dis 21:316-322

Zhang X, Wang R, Di X, Liu B, Liu Y (2014) Different microbiological and clinical aspects of lower respiratory tract infections between China and European/American countries. J Thorac Dis 6:134-142

Zheng X, Zhang G (2014) Imaging pulmonary infectious diseases in immunocompromised patients. Radiol Infect Dis 1:37-41. https ://doi.org/10.1016/j.jrid.2014.11.001

Zimlichman E et al (2013) Health care-associated infections: a metaanalysis of costs and financial impact on the US health care system. JAMA Intern Med 173:2039-2046

Publisher's Note Springer Nature remains neutral with regard to jurisdictional claims in published maps and institutional affiliations. 